\title{
CT-based study of vertebral and intravertebral rotation in right thoracic adolescent idiopathic scoliosis
}

\author{
Rob C. Brink ${ }^{1}$ - Jelle F. Homans ${ }^{1} \cdot$ Tom P. C. Schlösser ${ }^{1} \cdot$ Marijn van Stralen $^{2} \cdot$ Koen L. Vincken $^{3} \cdot$ Lin Shi $^{4}$. \\ Winnie C. W. Chu ${ }^{5} \cdot$ Max A. Viergever ${ }^{3} \cdot$ René M. Castelein $^{1} \cdot$ Jack C. Y. Cheng ${ }^{6}$
}

Received: 21 January 2019 / Accepted: 3 September 2019 / Published online: 11 September 2019

(c) The Author(s) 2019

\begin{abstract}
Purpose To define the longitudinal rotation axis around which individual vertebrae rotate, and to establish the various extraand intravertebral rotation patterns in thoracic adolescent idiopathic scoliosis (AIS) patients, for better understanding of the 3D development of the rotational deformity.

Methods Seventy high-resolution CT scans from an existing database of thoracic AIS patients (Cobb angle: $46^{\circ}-109^{\circ}$ ) were included to determine the vertebral axial rotation, rotation radius, intravertebral axial rotation, and local mechanical torsion for each spinal level, using previously validated image processing techniques.

Results For all levels, the longitudinal rotation axis, from which the vertebrae rotate away from the midline, was localized posterior to the spine. The axis became closer to the spine at the apex: apex, $r=11.5 \pm 5.1 \mathrm{~cm}$ versus two levels above (radius $=15.8 \pm 8.5 \mathrm{~cm} ; p<0.001$ ) and beneath (radius $=14.2 \pm 8.2 \mathrm{~cm} ; p<0.001$ ). The vertebral axial rotation, intravertebral axial rotation, and local mechanical torsion of the vertebral bodies were largest at the apex $\left(21.9^{\circ} \pm 7.4^{\circ}, 8.7^{\circ} \pm 13.5^{\circ}\right.$ and $\left.3.0^{\circ} \pm 2.5^{\circ}\right)$ and decreased toward the neutral, junctional zones $(p<0.001)$.

Conclusion In AIS, the vertebrae rotate away around an axis that is localized posterior to the spine. The distance between this axis and the spine is minimal at the apex and increases gradually to the neutral zones. The vertebral axial rotation is accompanied by smaller amounts of intravertebral rotation and local mechanical torsion, which increases toward the apical region. The altered morphology and alignment are important for a better understanding of the 3D pathoanatomical development of AIS and better therapeutic planning for bracing and surgical intervention.
\end{abstract}

\section{Graphic abstract}

These slides can be retrieved under Electronic Supplementary Material.
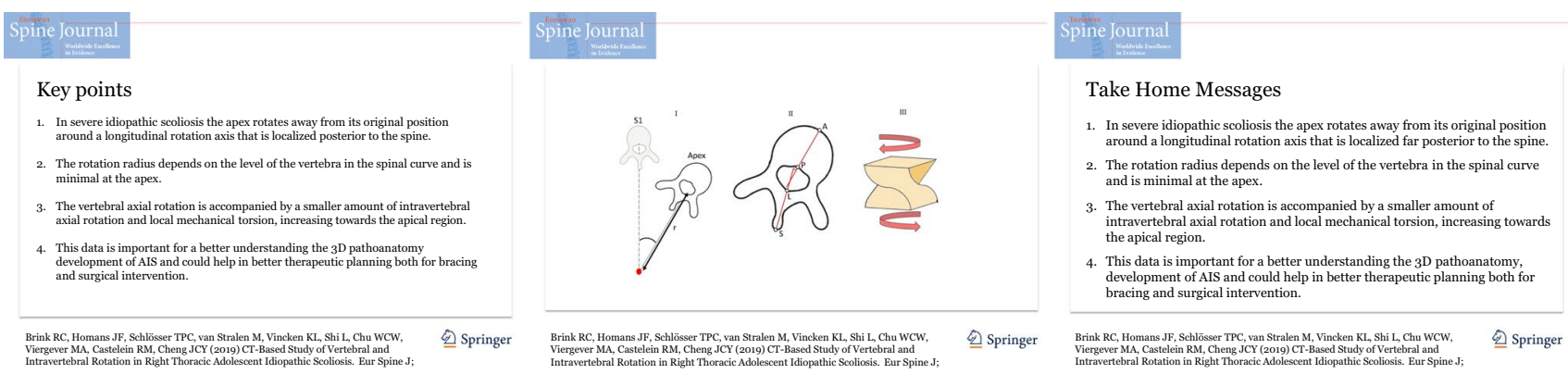

Keywords Adolescent idiopathic scoliosis · Longitudinal rotation axis · Axial rotation · Intravertebral axial rotation · Local mechanical torsion

Electronic supplementary material The online version of this article (https://doi.org/10.1007/s00586-019-06138-3) contains supplementary material, which is available to authorized users.

Extended author information available on the last page of the article 


\section{Introduction}

Despite many years of dedicated research into its cause, no single etiological mechanism has been established for adolescent idiopathic scoliosis (AIS) [1, 2]. Typical coronal radiographs of AIS patients include a lateral curvature of the spine, as well as vertebral rotation. One of its characteristics is that the apical vertebrae rotate away from the midline in a complex three-dimensional (3D) pattern $[3,4]$. The rotation of the vertebrae is part of the-to a large extent-unknown pathogenetic mechanism that leads to scoliosis. Earlier anatomical studies have looked at the longitudinal rotational axis of the normal spine, which is mostly located within the confines of the vertebral body; however, the results were contradicting and the exact position of the rotation axis, as well as the rotation pattern remains unclear [3,5-17]. Insight in the rotation mechanism of the different vertebrae within the curve and whether the rotation is mainly local (located within the vertebra: intravertebral axial rotation and local mechanical torsion), or a rotation of the whole segment (vertebral axial rotation) are important to help understand possible mechanisms of scoliosis development and a better description of the altered anatomy. Additionally, this knowledge could give more insights in the treatment of scoliosis, since reduction and restoration of the rotational deformity is one of the treatment goals. Therefore, the objective of this study is to systematically (according to the Scoliosis Research Society 3D Terminology of Spinal Deformity [18]) define all different extra- and intravertebral patterns of spinal rotation in the axial plane in idiopathic scoliosis patients: the vertebral axial rotation and the rotation radius, as well as the intravertebral axial rotation (the rotation between the vertebral body and posterior elements) and the local mechanical torsion (between the upper and lower endplate).

\section{Materials and methods}

\section{Study population}

This study has been approved by the local research ethics committees. Computed tomography (CT) scans of AIS patients were selected from an existing database, acquired for spinal navigation during posterior scoliosis surgery between 2011 and 2014, to establish the longitudinal rotation axis around which individual vertebrae rotate, as well as the various extra- and intravertebral rotation patterns of the thoracic AIS curve [19]. All cases that were diagnosed with a primary thoracic (Lenke curve type 1-4) right-convex scoliosis were included [20]. The complete preoperative workup consisted of standing posterior-anterior and lateral radiographs and supine bending radiographs, magnetic resonance imaging for screening of neural axis abnormalities, and CT imaging for navigation purposes. CT imaging (slice thickness of $0.625 \mathrm{~mm}$, in-plane resolution of $0.352 \mathrm{~mm} / \mathrm{pixel}, 64$ Slice Multidetector CT scanner, GE Healthcare, Chalfont, St. Giles, UK) was acquired in prone position, that was the standard workup in one of the medical centers during the inclusion period. No additional imaging was made for research purposes. Children with spinal pathology other than AIS, incomplete workup, or previous spinal surgery were excluded. In order to maximize homogeneity of the study population and power of the analyses, only curves with the most prevalent apical levels (between T8 and T10) were included [21]. Demographics and basic curve characteristics were determined by one observer (Table 1).

\section{CT measurement method}

Two trained observers used a semiautomatic image processing technique and software (ScoliosisAnalysis 4.1, Image Sciences Institute, Utrecht, the Netherlands, developed using MeVisLab, MeVis Medical Solutions AG, Bremen, Germany) to acquire complete spinal reconstructions in a $3 \mathrm{D}$ coordinate system. ScoliosisAnalysis 4.1 was described and validated in previous studies (Fig. 1) [22, 23]. Outcome parameters were defined according to the Scoliosis Research Society 3D Terminology of Spinal Deformity and were acquired using 3D segmentations of high-resolution CT scans [18]. The segmentation consisted of four steps.

Table 1 Demographics are shown for all included AIS patients

\begin{tabular}{lll}
\hline & & AIS $(n=70)$ \\
\hline Age (years) & Range & $10-26$ \\
& Mean \pm SD & $16.3 \pm 3.0$ \\
Girls, $n(\%)$ & & $59(84 \%)$ \\
Thoracic curve convexity, $n(\%)$ & Right convex & $70(100 \%)$ \\
Cobb angle primary thoracic curve $\left(^{\circ}\right)$ & Range & $46-109$ \\
& Mean \pm SD & $68.8 \pm 12.4$ \\
Thoracic kyphosis $\left(^{\circ}\right)$ & Range & -5 to 45 \\
Lenke type & Mean \pm SD & $26.2 \pm 10.3$ \\
& I & $37(53 \%)$ \\
& II & $21(30 \%)$ \\
& III & $9(13 \%)$ \\
Apex level primary thoracic curve & IV & $3(4 \%)$ \\
& Thoracic 8 & $18(26 \%)$ \\
& Thoracic 9 & $33(47 \%)$ \\
& Thoracic 10 & $19(27 \%)$ \\
\hline
\end{tabular}

$S D$ standard deviation 


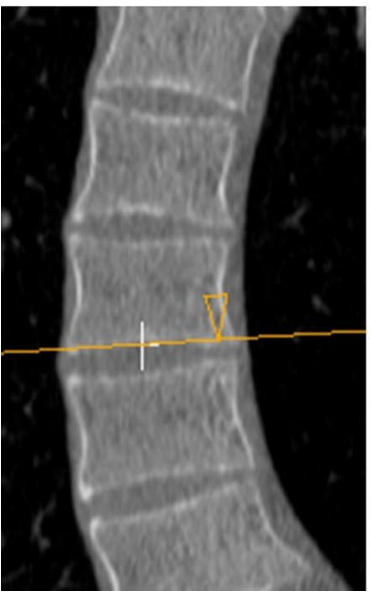

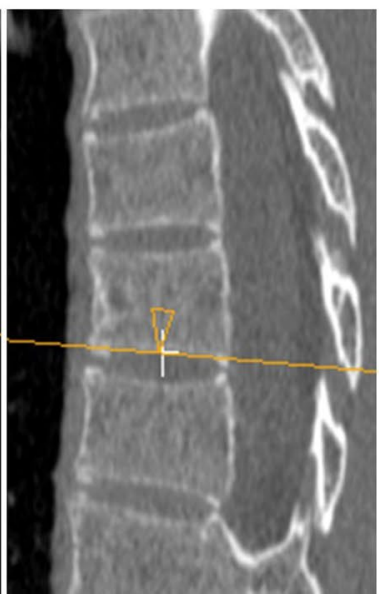

II

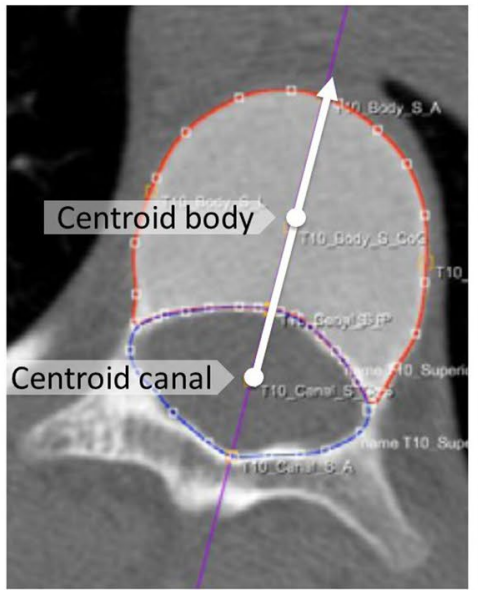

III

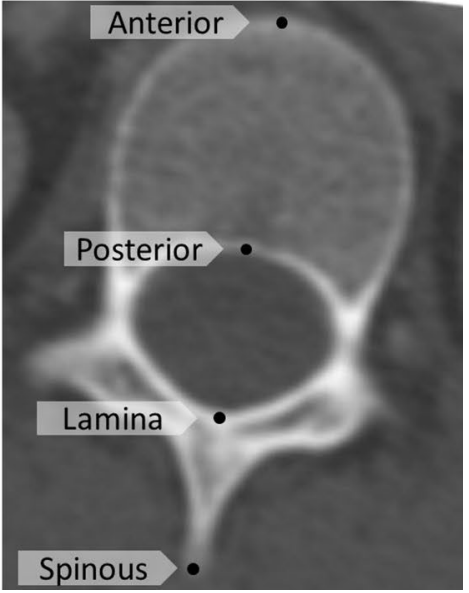

Fig. 1 The orientation of the upper and lower endplate of each individual vertebra of the computed tomography scans was determined by using the semiautomatic software, correcting for coronal and sagittal tilt (I), to reconstruct the true axial sections. The observer drew a contour around the vertebral body and spinal canal (II). The soft-

First, the observer drew a contour around the vertebral endplates and spinal canal which was corrected for coronal and sagittal tilt in order to reconstruct the true axial sections (Fig. 1). Second, based on the contour drawn by the observer, the software calculated a centroid of the vertebral body and spinal canal in 3D, taking account of angulation and displacement of each individual level in the coronal as ware calculated a centroid of the vertebral body and spinal canal and reconstructed a vertebral axis through these centroids (II). The intersections between this axis and the contours of the vertebral body create the anterior and posterior points (II, III). Next the observer segmented the lamina midpoint and the tip of the spinous process (III)

well as sagittal plane (Fig. 1). Third, a vertebral axis was automatically reconstructed through the centroid of the vertebral body and spinal canal in the axial plane. Fourth, the intersection of the vertebral axis and the contours of the vertebral endplate created automatically an anterior and posterior point of the vertebral endplate and the observer segmented the lamina midpoint and the tip of the spinous
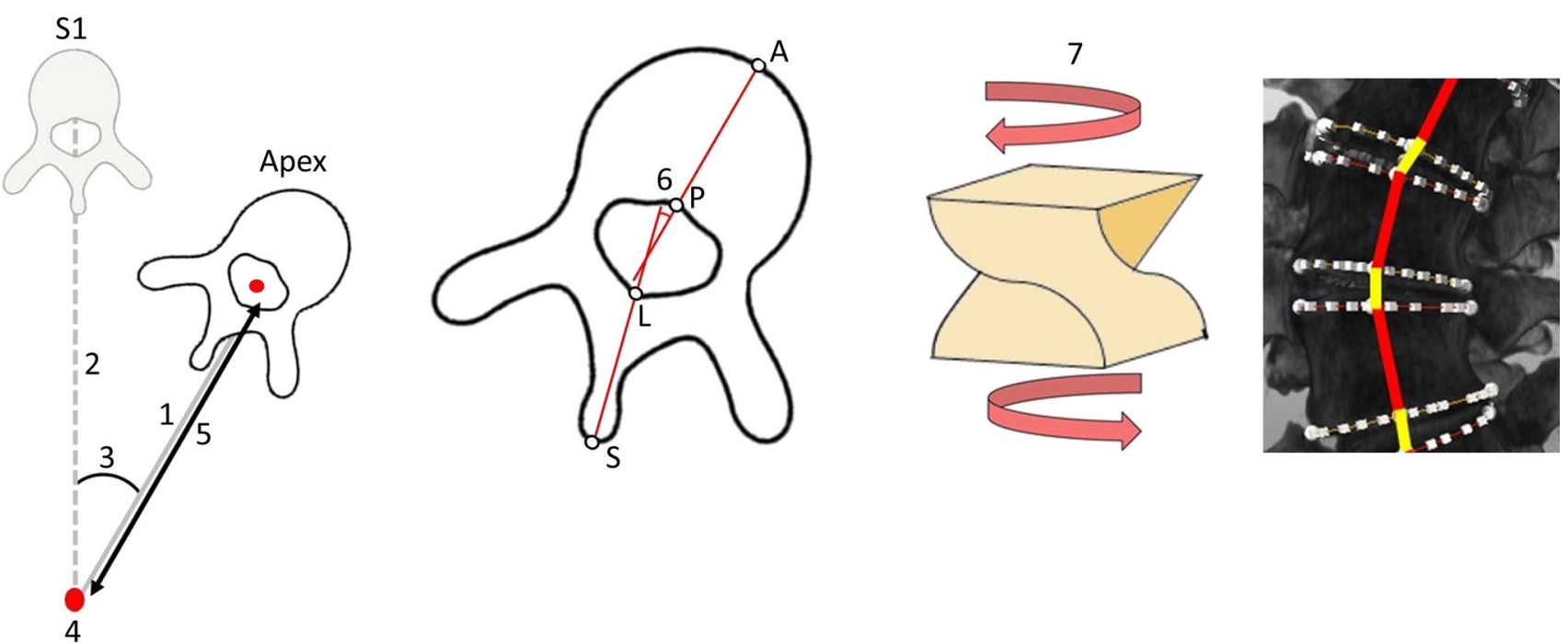

Fig. 2 The center of rotation of the vertebra was defined as the intersection between the vertebral axis (1) and the sacral axis (2). The vertebral axial rotation was defined as the angle between these axes (3). The longitudinal rotation axis (4) was defined as the intersection between the vertebral axis and the sacral axis and the rotation radius (5) as the distance between the longitudinal rotation axis and the cen- troid of the spinal canal. A line was reconstructed between the anterior $(\mathrm{A})$ and posterior $(\mathrm{P})$ points of the vertebra, as well as between the lamina (L) and spinous process (S) points (II). The angle between these lines defined the intravertebral axial rotation (6). Last, the local mechanical torsion was defined as the difference in rotation between the upper and lower endplate of the vertebra (7) 
process as well (Fig. 1). The vertebral axis of the sacral endplate, which was considered to have no rotation or translation in thoracic scoliosis, was used as the reference plane for the vertebral axial rotation (Fig. 2) [24, 25]. Since the longitudinal rotational axis moves farther from the spine in less rotated vertebrae, it is difficult to accurately determine the true neutral vertebrae. Therefore, this parameter was compared between the apical segment, one and two levels above $($ apex +1, apex +2$)$ and below (apex -1 , apex -2$)$ the apex.

\section{Outcome parameters}

The rotation radius was defined as the linear distance between the longitudinal rotation axis (the axis from which the vertebral bodies rotates away from the midline) to the center of the spinal canal of that corresponding vertebra (Figs. 1, 2). The vertebral axial rotation was measured as the angle between the vertebral axis (through the center of the vertebral body and spinal canal) and the sacral axis in the axial plane (Fig. 2). Next, the intravertebral axial rotation (between the vertebral body and posterior elements) was measured (Fig. 2). Last, the local mechanical torsion of the vertebral bodies was defined as the difference in axial rotation of the upper and lower endplate of the same vertebra (Fig. 2; Table 2).

\section{Statistical analysis}

Statistical analyses were performed using SPSS 22.0 for Windows (SPSS Inc., Chicago, IL, USA). Descriptive statistics were computed providing means, ranges, and standard deviations. Differences between different levels at, above and under the apex were analyzed with a one-way repeated measured analysis of variances (ANOVA) added with a post hoc pairwise comparison between each level (without contrast), using Bonferroni correction. The statistical significance level was set at 0.05 for all analyses. Statistical analyses were performed in terms of intra- and interobserver variability, which were obtained as intraclass correlation coefficients for the rotation radius and intravertebral axial rotation; two observers independently analyzed a randomly selected subset of 10 CT scans. The reliability of the vertebral axial rotation and the local mechanical torsion were measured in a previous study; intraclass correlation coefficients for intra- and interobserver reliability were 0.92 (95\% CI $0.82-0.97)$ and $0.89(0.74-0.95)[23]$.

\section{Results}

The database consisted of $98 \mathrm{CT}$ scans, and 28 were excluded (12 had associated congenital or neuromuscular pathologies, 11 had incomplete radiological charts, four had an atypical left convex thoracic curve, and one had undergone scoliosis surgery prior to obtaining the CT scan); thus a total of 70 AIS patients were included, with an average age of $16.3 \pm 3.0$ years (range 10-26). Coronal Cobb angle of the main thoracic curve varied between $46^{\circ}$ and $109^{\circ}$, and other demographics are shown in Table 1 [19].

\section{Longitudinal rotation axis and vertebral axial rotation}

The longitudinal rotation axis (mean $\pm \mathrm{SD}$ ) of the apex was on average $11.5 \pm 5.1 \mathrm{~cm}$ posterior to the centroid of the spinal canal of the apex. The radius length was smallest at the apical levels and increased further away from the apex (apex $+215.8 \pm 8.5 \mathrm{~cm}$, apex $+112.4 \pm 5.8 \mathrm{~cm}$, apex -1 $12.2 \pm 5.8 \mathrm{~cm}$, apex $-214.2 \pm 8.2 \mathrm{~cm}$ ). Repeated-measures ANOVA determined that the radius differed between the levels $(F(157.7,2.3)=11.4, p<0.001$; Fig. 3$)$. The vertebral axial rotation was largest at the apex $\left(21.9^{\circ} \pm 7.4^{\circ}\right)$ and decreased toward the neutral zone (apex $+214.2^{\circ} \pm 6.9^{\circ}$, apex $+119.5^{\circ} \pm 7.1^{\circ}$, apex $-120.2^{\circ} \pm 7.5^{\circ}$, apex -2 $\left.15.3^{\circ} \pm 8.0^{\circ}\right)$. Repeated-measures ANOVA: $F(104.5$, $1.5)=61.4, p<0.001$ (Fig. 4).

Table 2 Definitions of the outcome parameters

\begin{tabular}{|c|c|c|}
\hline Parameter & Definition & $\begin{array}{l}\text { Number } \\
\text { in Fig. } 2\end{array}$ \\
\hline Vertebral axis & Axis through the center of the vertebral body and spinal canal in the axial plane & 1 \\
\hline Sacral axis & Vertebral axis of the sacral endplate (neutral) & 2 \\
\hline Vertebral axial rotation & Angle between the vertebral axis and the sacral axis in the axial plane & 3 \\
\hline Longitudinal rotation axis & $\begin{array}{l}\text { Axis from which the vertebral bodies rotates away from the midline; the intersection between the verte- } \\
\text { bral axis and the sacral axis }\end{array}$ & 4 \\
\hline Rotation radius & $\begin{array}{l}\text { Linear distance between the longitudinal rotation axis to the center of the spinal canal of that corre- } \\
\text { sponding vertebra }\end{array}$ & 5 \\
\hline Intravertebral axial rotation & Rotation between the vertebral body and posterior elements & 6 \\
\hline Local mechanical torsion & Difference in axial rotation of the upper and lower endplate of the same vertebra & 7 \\
\hline
\end{tabular}



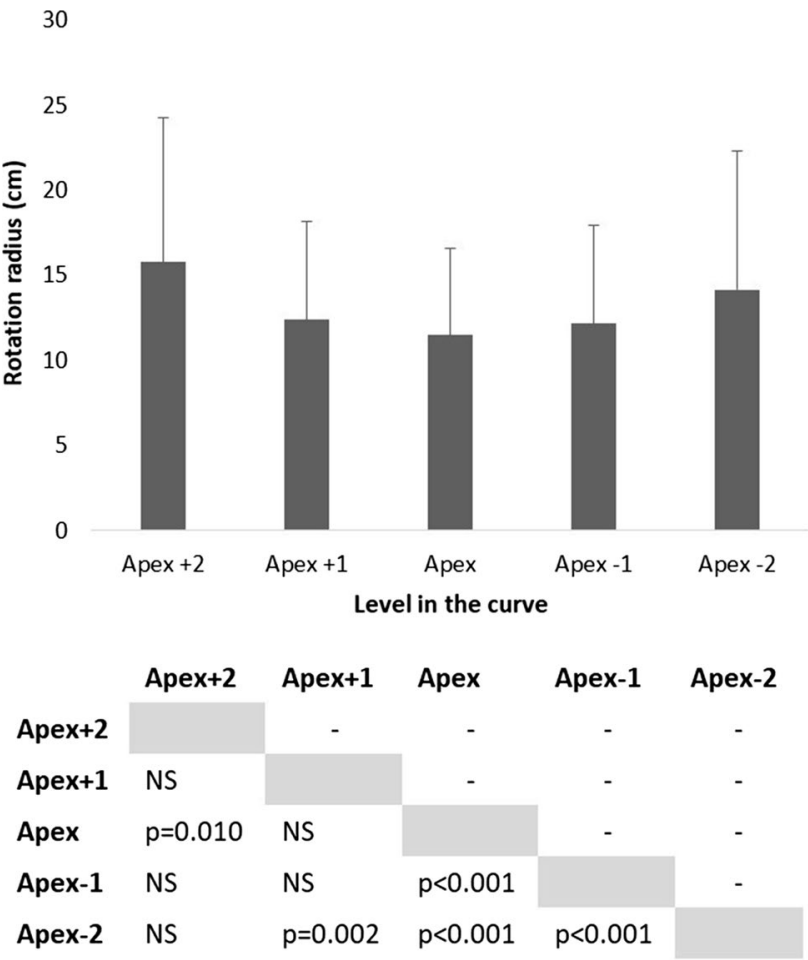

Fig. 3 The rotation radius of the apical vertebra and the two above and below is shown, including standard deviation (error bars). Below, the statistical significance level is shown between the different levels. $\mathrm{NS}=$ not significant

\section{Intravertebral axial rotation and local mechanical torsion}

The angle between the vertebral bodies and posterior elements (intravertebral axial rotation) was largest at the apex $\left(8.7^{\circ} \pm 13.5^{\circ}\right)$ and decreased further away from the apex (apex $+21.1^{\circ} \pm 8.4^{\circ}$, apex $+1: 5.4^{\circ} \pm 10.2^{\circ}$, apex -1 : $3.7^{\circ} \pm 8.8^{\circ}$, apex $\left.-21.8^{\circ} \pm 8.8^{\circ}\right)$. Repeated-measures ANOVA determined that the intravertebral axial rotation differed between the levels $(F(233.5,3.4)=7.5, p<0.001$; Fig. 5). The local mechanical torsion differed between the different levels of the curve (apex $+23.3^{\circ} \pm 2.4^{\circ}$, apex +1 $2.2^{\circ} \pm 1.7^{\circ}$, apex $3.0^{\circ} \pm 2.5^{\circ}$ apex $-13.8^{\circ} \pm 2.5^{\circ}$, apex -2 $\left.3.2^{\circ} \pm 2.1^{\circ}\right)$. Repeated-measures ANOVA: $F(276,4)=5.5$, $p<0.001$ (Fig. 6)

\section{Reliability}

Intraclass correlation coefficients for intra- and interobserver reliabilities were 0.95 (95\% CI 0.91-0.97) and 0.96 $(0.93-0.98)$ for the rotation radius and $0.99(0.97-1.00)$ and $0.97(0.93-0.99)$ for the intravertebral axial rotation, respectively.
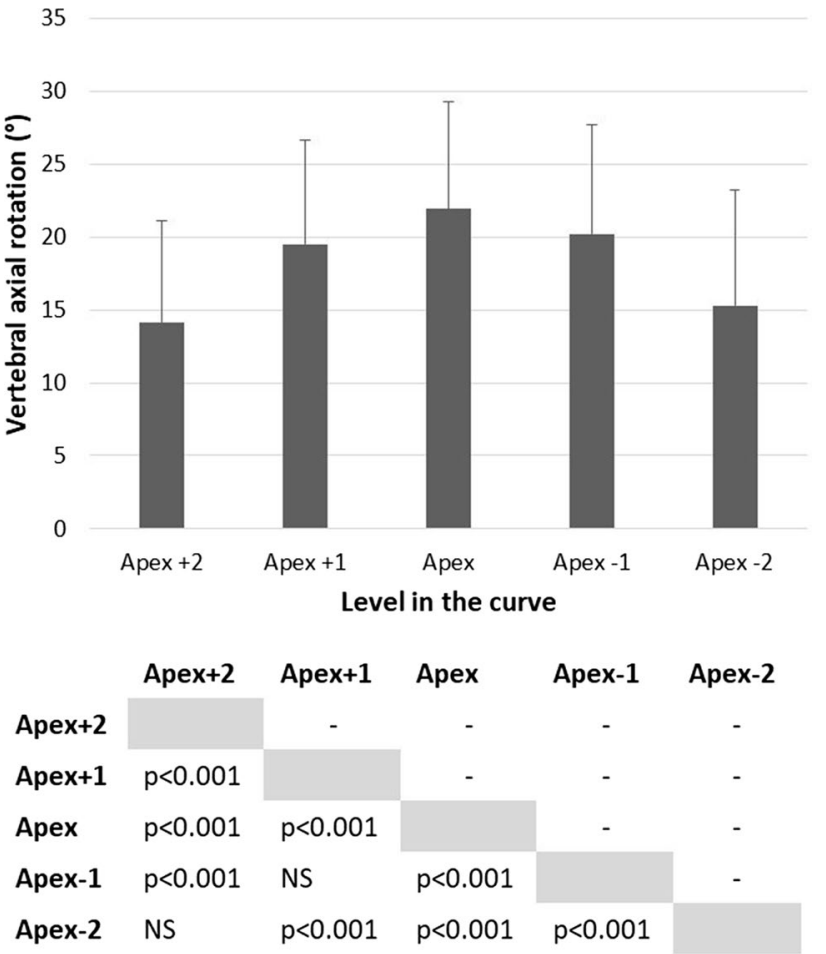

Fig. 4 The vertebral axial rotation of the apical vertebra and the two above and below is shown, including standard deviation (error bars). Below, the statistical significance level is shown between the different levels. NS $=$ not significant

\section{Discussion}

The non-scoliotic spine is only slightly rotated in the axial plane, is coronally aligned without a curvature, and shows mild kyphotic and lordotic curvatures in the thoracic and sacral, respectively, the cervical and lumbar regions [22, 23]. In idiopathic scoliosis, due to a still unknown cause, each vertebra in the curve rotates away from its normal position. This rotation can be described by the location of the longitudinal rotation axis around which this occurs. Vertebral axial rotation has, to a large extent, been studied in vitro and also in non-scoliotic spines. Within these studies, the longitudinal rotation axis was found to be determined by the orientation of the facet joints and to lay mainly within the confines of the vertebra $[5,9-12,15]$. However, the position of the longitudinal rotation axis and the different extra- and intravertebral rotation patterns of the scoliotic spine are still unknown, while the treatment and most etiological concepts are largely based on rotation.

Our study showed the longitudinal rotation axis of the scoliotic apical vertebrae appeared to lie far dorsal from the spine itself, on average $11.5 \mathrm{~cm}$ and differed per level in the spine. If there is much vertebral axial rotation, as in the apical vertebral body, the longitudinal rotation axis becomes closer to the vertebra. In the less rotated vertebrae 

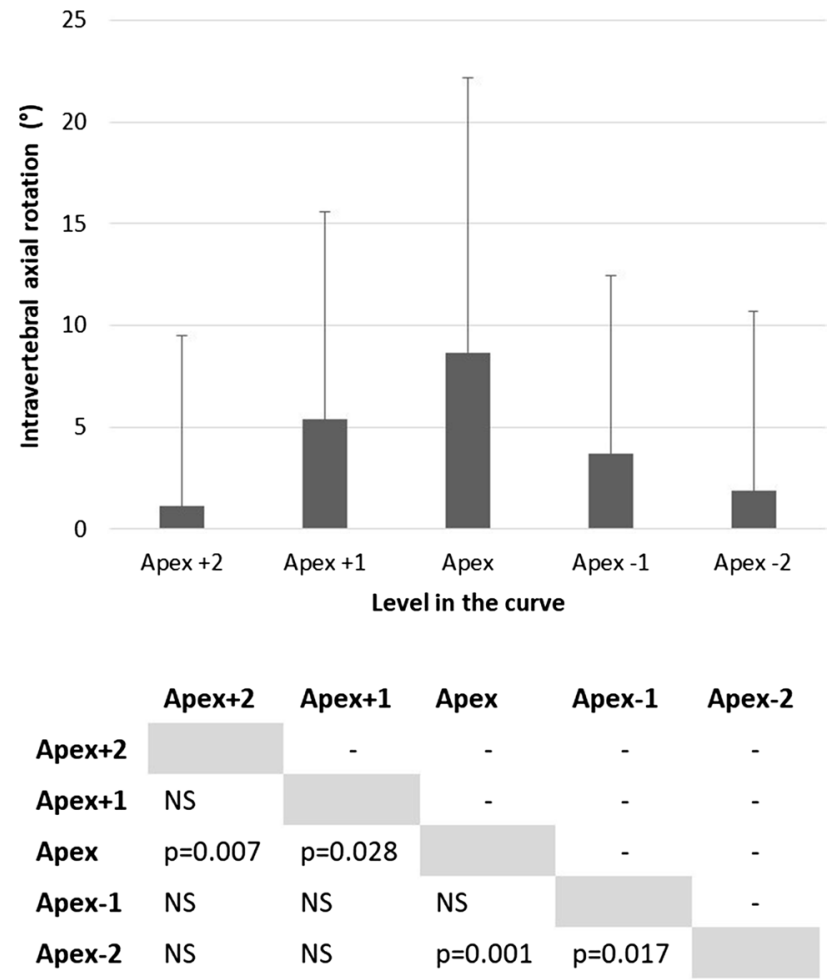

Fig. 5 The intravertebral axial rotation of the apical vertebra and the two above and below is shown, including standard deviation (error bars). Below, the statistical significance level is shown between the different levels. $\mathrm{NS}=$ not significant

near the end of the curve, the intersection lies farther away. The longitudinal rotation axis of the different levels in the curve formed a parabolic shape in the sagittal plane (Fig. 3). Furthermore, the vertebral axial rotation was $21.9^{\circ} \pm 7.4^{\circ}$ at the apical vertebrae, and the intravertebral axial rotation and local mechanical torsion of the apex were $8.7^{\circ} \pm 13.5^{\circ}$ and $3.0^{\circ} \pm 2.5^{\circ}$. Analogous to the rotation axis, the axial rotation was largest at the apex and decreased toward the neutral zone. The larger rotation at the apex is in line with the increased 3D wedging and asymmetry of the apex, compared with the neutral zone, as described in previous studies $[17,23,24,26]$. The rotation of the whole segment (axial rotation) is much larger than the rotation within the vertebra (intravertebral rotation). This difference contradicts an exaggerated asymmetrical bone growth as cause of the rotation, but a longitudinal study design is necessary for this purpose.

In contrast to the previous studies, the longitudinal axis of rotation of this study is based on the vertebral axial rotation, as well as the translation in the coronal plane. White and Panjabi were among the first to describe the longitudinal rotational axis. Based on their study, the axis was found to lay within the vertebral body [15]. Most other authors found this axis somewhere within the confines of the vertebra $[9,11,12]$. Others, including Nash and Moe
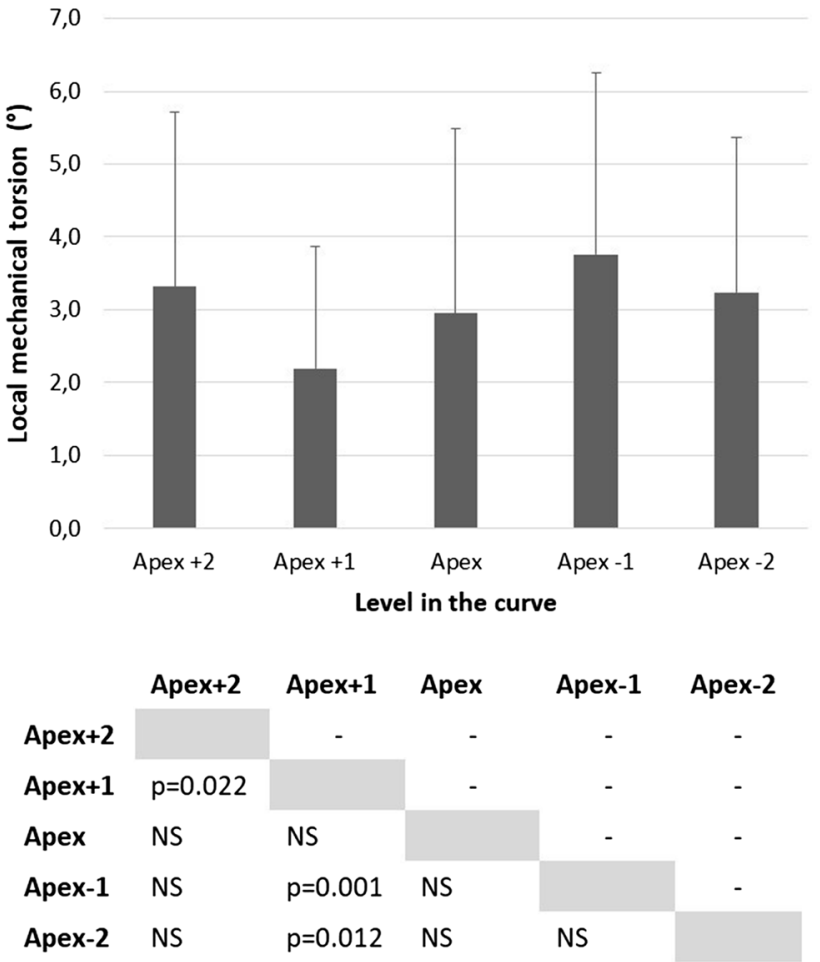

Fig. 6 The local mechanical torsion of the apical vertebra and the two above and below is shown, including standard deviation (error bars). Below, the statistical significance level is shown between the different levels. $\mathrm{NS}=$ not significant

and Molnar et al., demonstrated that the longitudinal rotation axis lies at the posterior side of the vertebral body, whereas Roaf and Lindahl observed it even more posteriorly (Roaf close to the tip of the spinous processes, and Lindahl at the tip of the transverse processes) $[3,5,9$, $14,27]$. The major limitation, however, is that all these rotational axes are based on non-scoliotic specimens, cadaveric spines, or models. Last decades, other authors described the vertebral rotation of the scoliotic spine using $2 \mathrm{D}$ or $3 \mathrm{D}$ imaging [17, 22, 28-31]. Smith et al. hypothesized that if there is a thoracic lordosis, instead of the normal thoracic kyphosis, the longitudinal rotation axis is located posteriorly to the spine, based on two human skeletons with scoliosis and an animal study [10]. Kotwicki et al. [16] observed an average angulation of $15.0^{\circ}$ between the vertebral body axis and spinous process axis. Additionally, Kotwicki et al. [16] described the direction of the rotation of the vertebra and spinous process, that is similar to the results of this study. The vertebral body is pushed away from the midline, whereas the spinous process is less pushed away from the midline, probably stabilized by the posterior ligaments, corresponding with the posterior located longitudinal rotation axis (Fig. 2). They described that the bone remodeling of the vertebral body and the spinous process deviation act, parallel in time, in opposite 
direction, as an extension of the theory by Smith et al. [10] and Kotwicki and Napiontek [16]. Recently, Vavruch et al. [17] described the vertebral rotation and internal deformation. The asymmetry was observed in the apex, decreasing toward the neutral vertebra (the most cephalad vertebra below the apex of the major curve whose pedicles are symmetrically located within the radiographic silhouette of the vertebral body) [17].

Despite the detailed description of the vertebral rotation, the longitudinal rotation axis of the scoliotic spine and the different aspects of the rotation mechanism of the vertebrae within the curve were not described before. The present study confirms that, in scoliosis, unlike what is described for the normal spine, the longitudinal rotation axis consistently lies behind the spinal column and its position along the curve shows a parabolic distribution, implying that during the derotation procedure of the treatment, different strategies are necessary for the vertebrae along the curve. It is well known that the thoracic kyphosis of the normal anatomy is deformed in a thoracic lordosis in moderate to severe scoliosis [24, 32-36]. This mechanism influences partly the posterior position of the rotation axis as well. Additionally, further aspects of the rotation (vertebral axial rotation, intravertebral axial rotation and local mechanical torsion) were described to clarify the rotation mechanism of scoliosis, to help understand possible mechanisms of scoliosis development and treatments.

This study provides an estimation of the rotational axis of different levels inside the curve and the differences between the axial rotation of the vertebra and the intravertebral torsion. CT scanning is considered the gold standard for studying rotation in the scoliotic spine, but leads to limitations as well [37]. First, CT scans are not made in upright, but in prone position. Previous studies have shown that both Cobb angle and vertebral rotation are influenced by body position [38-42]. The longitudinal rotational axis is likely to vary between different body positions as well. However, data on the longitudinal rotational axis of the vertebrae in the normal spine are usually not obtained upright either, and based on the mentioned comparative studies between different body positions, the observed phenomena in our present study probably only differ quantitatively, not qualitatively from an upright position. Second, for this study, an already existing CT database was used, acquired as part of the general preoperative workup for navigation-guided pedicle screw surgery in one of our institutions, resulting in a cross-sectional study design, including only severe AIS patients. A longitudinal study, including milder curves as well, might provide more insight into the rotation mechanism during the progression of the scoliosis, which hopefully could be done with future validated reliable non-ionizing radiation assessment such as ultrasound and others.

\section{Conclusion}

Axial rotational instability is an important factor in the pathomechanism of idiopathic scoliosis, but remained unknown to a large extend. This study showed the altered morphology and alignment which is important for a better understanding the 3D pathoanatomy and the development of AIS and could help in better therapeutic planning both for bracing and for surgical intervention. The key observation is that in severe idiopathic scoliosis the apex rotates away from its original position around a longitudinal rotation axis that is localized far posterior to the spine; the distance depends on the level of the vertebra in the spinal curve. The vertebral axial rotation is accompanied by a smaller amount of intravertebral axial rotation and local mechanical torsion, increasing toward the apical region.

Funding Funding was provided by K2M Research Grant, Alexandre Suerman MD/PhD Grant.

\section{Compliance with ethical standards}

Conflict of interest The authors declare that they have no conflict of interest.

Open Access This article is distributed under the terms of the Creative Commons Attribution 4.0 International License (http://creativeco mmons.org/licenses/by/4.0/), which permits unrestricted use, distribution, and reproduction in any medium, provided you give appropriate credit to the original author(s) and the source, provide a link to the Creative Commons license, and indicate if changes were made.

\section{References}

1. Kouwenhoven JW, Castelein RM (2008) The pathogenesis of adolescent idiopathic scoliosis: review of the literature. Spine 33:2898-2908

2. Cheng JC, Castelein RM, Chu WC, Danielsson AJ, Dobbs MB, Grivas TB, Gurnett CA, Luk KD, Moreau A, Newton PO, Stokes IA, Weinstein SL, Burwell GR (2015) Adolescent idiopathic scoliosis. Nat Rev Dis Primers 1:15030

3. Roaf R (1966) The basic anatomy of scoliosis. J Bone Joint Surg $\mathrm{Br}$ 48:786-792

4. Somerville EW (1952) Rotational lordosis; the development of single curve. J Bone Joint Surg Br 34-B:421-427

5. Nash CL Jr, Moe JH (1969) A study of vertebral rotation. J Bone Joint Surg Am 51:223-229

6. Labelle H, Aubin CE, Jackson R, Lenke L, Newton P, Parent S (2011) Seeing the spine in 3D: how will it change what we do? J Pediatr Orthop 31:S37-45

7. Illes T, Somoskeoy S (2013) Comparison of scoliosis measurements based on three-dimensional vertebra vectors and conventional two-dimensional measurements: advantages in evaluation of prognosis and surgical results. Eur Spine J 22:1255-1263 
8. Parent S, Labelle H, Skalli W, Latimer B, de Guise J (2002) Morphometric analysis of anatomic scoliotic specimens. Spine 27:2305-2311

9. Molnar S, Mano S, Kiss L, Csernatony Z (2006) Ex vivo and in vitro determination of the axial rotational axis of the human thoracic spine. Spine 31:E984-E991

10. Smith RM, Pool RD, Butt WP, Dickson RA (1991) The transverse plane deformity of structural scoliosis. Spine 16:1126-1129

11. Louis R (1983) Surgery of the spine. Surgical anatomy and operative approaches, 1st edn. Springer, New York

12. Gregersen GG, Lucas DB (1967) An in vivo study of the axial rotation of the human thoracolumbar spine. J Bone Joint Surg Am 49:247-262

13. Lindahl O (1966) Resection of vertebral transverse processes in idiopathic scoliosis. Acta Orthop Scand 37:342-347

14. Bouillet R, Vincent A (1967) Idiopathic scoliosis. Acta Orthop Belg 33:93-388

15. White AA, Panjabi MM (1978) Clinical biomechanics of the spine, 1st edn. J.B. Lippincott Company, Philadephia

16. Kotwicki T, Napiontek M (2008) Intravertebral deformation in idiopathic scoliosis: a transverse plane computer tomographic study. J Pediatr Orthop 28:225-229

17. Vavruch L, Forsberg D, Dahlstrom N, Tropp H (2018) Vertebral axial asymmetry in adolescent idiopathic scoliosis. Spine Deform 6:112-120.e1

18. Stokes IA (1994) Three-dimensional terminology of spinal deformity. A report presented to the Scoliosis Research Society by the Scoliosis Research Society Working Group on 3-D terminology of spinal deformity. Spine 19:236-248

19. Lenke LG, Edwards CC, Bridwell KH 2nd (2003) The Lenke classification of adolescent idiopathic scoliosis: how it organizes curve patterns as a template to perform selective fusions of the spine. Spine 28:S199-207

20. Lenke LG, Betz RR, Harms J, Bridwell KH, Clements DH, Lowe TG, Blanke K (2001) Adolescent idiopathic scoliosis: a new classification to determine extent of spinal arthrodesis. J Bone Joint Surg Am 83-A:1169-1181

21. Fujimori T, Bastrom TP, Bartley CE, Newton PO, Harms Study Group (2014) Comparison of typical thoracic curves and atypical thoracic curves within the Lenke 1 classification. Spine Deform 2:308-315

22. Kouwenhoven JW, Vincken KL, Bartels LW, Castelein RM (2006) Analysis of preexistent vertebral rotation in the normal spine. Spine 31:1467-1472

23. Schlösser TP, van Stralen M, Brink RC, Chu WC, Lam TP, Vincken KL, Castelein RM, Cheng JC (2014) Three-dimensional characterization of torsion and asymmetry of the intervertebral discs versus vertebral bodies in adolescent idiopathic scoliosis. Spine 39(19):E1159-E1166

24. Schlösser TP, van Stralen M, Chu WC, Lam TP, Ng BK, Vincken KL, Cheng JC, Castelein RM (2016) Anterior overgrowth in primary curves, compensatory curves and junctional segments in adolescent idiopathic scoliosis. PLoS ONE 11:e0160267

25. Kashimoto T, Yamamuro T, Hatakeyama K (1982) Anatomical and biomechanical factors in the curve pattern formation of idiopathic scoliosis. Acta Orthop Scand 53:361-368

26. Brink RC, Schlösser TP, Colo D, Vincken KL, van Stralen M, Hui SC, Chu WC, Cheng JC, Castelein RM (2017) Asymmetry of the vertebral body and pedicles in the true transverse plane in adolescent idiopathic scoliosis: a CT-based study. Spine Deform $5: 37-45$
27. Lindahl O, Raeder E (1962) Mechanical analysis of forces involved in idiopathic scoliosis. Acta Orthop Scand 32:27-38

28. Aaro S, Dahlborn M (1981) Estimation of vertebral rotation and the spinal and rib cage deformity in scoliosis by computer tomography. Spine 6:460-467

29. Aaro S, Dahlborn M (1981) The longitudinal axis rotation of the apical vertebra, the vertebral, spinal, and rib cage deformity in idiopathic scoliosis studied by computer tomography. Spine 6:567-572

30. Vrtovec T, Pernus F, Likar B (2009) A review of methods for quantitative evaluation of axial vertebral rotation. Eur Spine $\mathbf{J}$ 18:1079-1090

31. Cobb JR (1948) Outline for the study of scoliosis. In: Instructional course lectures, vol 5, 2nd edn. The American Academy of Orthopaedic Surgeons, Instructional Course Lectures. p 261

32. Brink RC, Schlösser TP, Colo D, Vavruch L, van Stralen M, Vincken KL, Malmqvist M, Kruyt MC, Tropp H, Castelein RM (2016) Anterior spinal overgrowth is the result of the scoliotic mechanism and is located in the disc. Spine 42(11):818-822

33. Raso VJ, Russell GG, Hill DL, Moreau M, McIvor J (1991) Thoracic lordosis in idiopathic scoliosis. J Pediatr Orthop 11:599-602

34. Dickson RA, Lawton JO, Archer IA, Butt WP (1984) The pathogenesis of idiopathic scoliosis. Biplanar spinal asymmetry. J Bone Joint Surg Br 66:8-15

35. Guo X, Chau WW, Chan YL, Cheng JC (2003) Relative anterior spinal overgrowth in adolescent idiopathic scoliosis. Results of disproportionate endochondral-membranous bone growth. J Bone Joint Surg Br 85:1026-1031

36. Chu WC, Lam WW, Chan YL, Ng BK, Lam TP, Lee KM, Guo X, Cheng JC (2006) Relative shortening and functional tethering of spinal cord in adolescent idiopathic scoliosis?: study with multiplanar reformat magnetic resonance imaging and somatosensory evoked potential. Spine 31:E19-25

37. Glaser DA, Doan J, Newton PO (2012) Comparison of 3-dimensional spinal reconstruction accuracy: biplanar radiographs with EOS versus computed tomography. Spine 37:1391-1397

38. Brooks HL, Azen SP, Gerberg E, Brooks R, Chan L (1975) Scoliosis: a prospective epidemiological study. J Bone Joint Surg Am 57:968-972

39. Wessberg P, Danielson BI, Willen J (2006) Comparison of Cobb angles in idiopathic scoliosis on standing radiographs and supine axially loaded MRI. Spine 31:3039-3044

40. Lee MC, Solomito M, Patel A (2013) Supine magnetic resonance imaging Cobb measurements for idiopathic scoliosis are linearly related to measurements from standing plain radiographs. Spine 38:E656-E661

41. Shi B, Mao S, Wang Z, Lam TP, Ping Yu FW, Wah Ng BK, Chu WC, Zhu Z, Qiu Y, Yiu Cheng JC (2015) How does the supine MRI correlate with standing X-ray of different curve severity in adolescent idiopathic scoliosis? Spine 40(15):1206-1212

42. Brink R, Colo C, Schlösser T, vanStralen M, Hui S, Chu W, Cheng J, Castelein R (2017) Upright, prone and supine spinal morphology and alignment in adolescent idiopathic scoliosis. Scoliosis Spinal Disord 22(12):6

Publisher's Note Springer Nature remains neutral with regard to jurisdictional claims in published maps and institutional affiliations. 


\section{Affiliations}

\section{Rob C. Brink ${ }^{1}$. Jelle F. Homans ${ }^{1} \cdot$ Tom P. C. Schlösser ${ }^{1} \cdot$ Marijn van Stralen ${ }^{2} \cdot K^{1}$ Ken L. Vincken ${ }^{3} \cdot$ Lin Shi $^{4}$.} Winnie C. W. Chu ${ }^{5} \cdot$ Max A. Viergever ${ }^{3} \cdot$ René M. Castelein $^{1} \cdot$ Jack C. Y. Cheng ${ }^{6}$

Rob C. Brink

r.c.brink@umcutrecht.nl

$\triangle$ René M. Castelein

r.m.castelein@umcutrecht.nl

1 Department of Orthopaedic Surgery, G05.228, University Medical Center Utrecht, P.O. Box 85500, 3508 GA Utrecht, The Netherlands

2 Imaging Division, University Medical Center Utrecht, Utrecht, The Netherlands

3 Image Sciences Institute, University Medical Center Utrecht, Utrecht, The Netherlands
4 Department of Diagnostic Radiology and Organ Imaging, Prince of Wales Hospital, The Chinese University of Hong Kong, Shatin, Hong Kong

5 Department of Imaging and Interventional Radiology, Prince of Wales Hospital, The Chinese University of Hong Kong, Shatin, Hong Kong

6 Department of Orthopaedics and Traumatology, Prince of Wales Hospital, The Chinese University of Hong Kong, Shatin, Hong Kong 